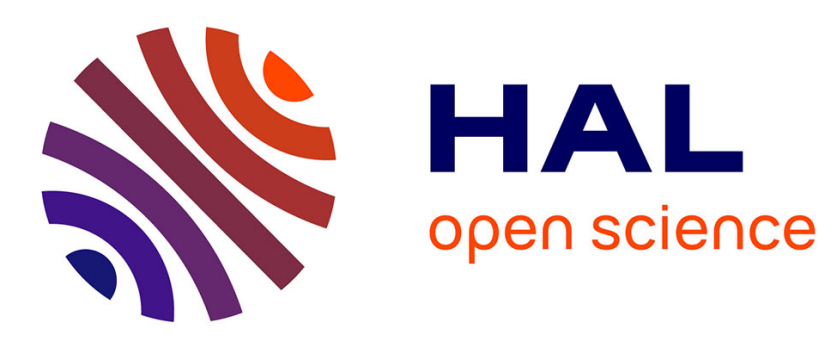

\title{
An Affordable and Easy-to-Use Interferometer with a Dedicated Acquisition System
}

Walid-Adel Merzouk, Barthélemy Cagneau, Khalid Hilouane, Luc Chassagne, Florent Gardillou

\section{- To cite this version:}

Walid-Adel Merzouk, Barthélemy Cagneau, Khalid Hilouane, Luc Chassagne, Florent Gardillou. An Affordable and Easy-to-Use Interferometer with a Dedicated Acquisition System. IEEE Sensors 2016, Oct 2016, Orlando, United States. hal-01378073

\section{HAL Id: hal-01378073 \\ https://hal.science/hal-01378073}

Submitted on 8 Oct 2016

HAL is a multi-disciplinary open access archive for the deposit and dissemination of scientific research documents, whether they are published or not. The documents may come from teaching and research institutions in France or abroad, or from public or private research centers.
L'archive ouverte pluridisciplinaire HAL, est destinée au dépôt et à la diffusion de documents scientifiques de niveau recherche, publiés ou non, émanant des établissements d'enseignement et de recherche français ou étrangers, des laboratoires publics ou privés. 


\section{An Affordable and Easy-to-Use Interferometer with a Dedicated Acquisition System}

\author{
Walid-Adel Merzouk, Barthélemy Cagneau, Khalid \\ Hilouane, Luc Chassagne \\ Université de Versailles Saint-Quentin en Yvelines \\ UVSQ / LISV \\ Vélizy, France \\ barthelemy.cagneau@uvsq.fr
}

\author{
Florent Gardillou \\ Teemphotonics \\ Meylan, France \\ f.gardillou@teemphotonics.com
}

\begin{abstract}
In this paper, we present an affordable interferometer with its dedicated electronics system. The interferometer uses an infrared source and is based on a telecom waveguide technology. The electronics part has been fully developed in our laboratory with available commercial components. Experimental results are provided and compared to those obtained with a computer and commercial acquisition boards.
\end{abstract}

\section{Keywords-interferometry; nanoscale; embedded system}

\section{INTRODUCTION}

In the literature, several sensors exist for applications dedicated to nanoscales like topography, lithography or microand nano-objects positioning and manipulation. In this particular scope, we are interested in precise positioning systems over a long displacement range (a few centimeters). As explained in [1], some sensors already exist in order to control a system with a nanometric resolution and/or accuracy. It includes not only interferometers but also piezoelectric devices, strain or inductive sensors and encoders. In [2], encoders that may reach nanometric performances are presented. However, the available stroke as well as the price of the sensors are still some drawbacks inherent to these technologies. In [3], a system composed of 2 emitting and collecting fibers is proposed. However, this system is affected by drifts when long term measurement is required. In [4] and [5], a sensor based on CCD and photodiode arrays is presented. The position is computed with triangulation techniques. The bandwidth is however limited and the compactness of the system is another issue.

The interferometers [6] appear as a good solution when both long stroke and resolution are concerned. However, the price of such sensors may be quite high especially for systems with mutli degrees of freedom. In this case, several sensors must be integrated to perform closed-loop control of the system.

In this paper, we present a compact and affordable interferometer since we have developed an acquisition system made of commercial components to compute the position on an embedded system. In section II, we present the new version of the PicoMove system presented in [7]. The results are presented in section III and a conclusion is drawn in section IV.

\section{INTERFEROMETER CHIP}

\section{A. Optical Path}

Fig.1 represents the optical path in the internal chip. The wavelength of the source is $1550 \mu \mathrm{m}$. The system is convenient to use and the cost is limited since the source is widely used for telecom applications.

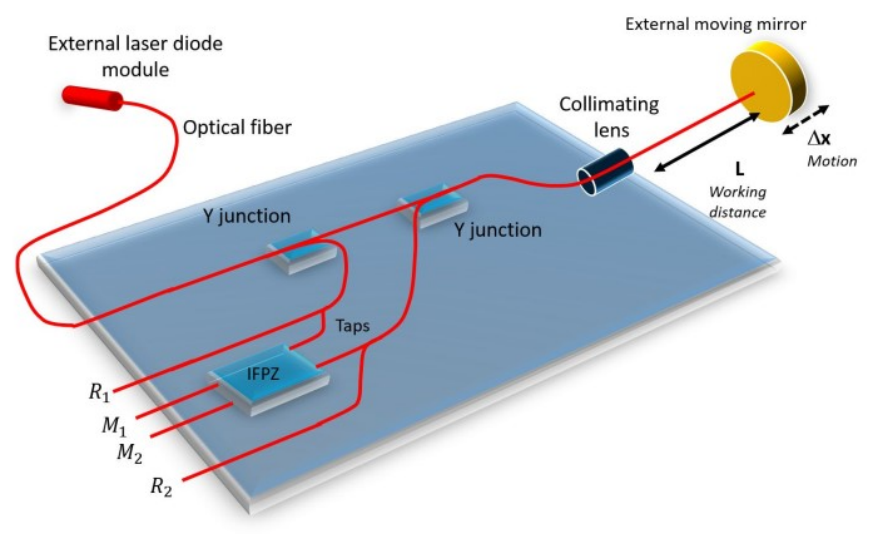

Fig. 1: Optical path

$R_{1}$ and $R_{2}$ are the two references for the two arms of the interferometer (parts of the incoming and retro injected signals). $M_{1}$ and $M_{2}$ are the 2 quadrature outputs signals. The four outputs are linked to a photodetector module which converts the optical waves into voltages through a classical transimpedance circuit. The optical interference between the reference path and the mobile path is made in the Interference Free-Propagation Zone (IFPZ in Fig. 1). The new version of the system used in this paper has been designed by Teem Photonics. It consists of an optical chip with integrated waveguides. That makes the interferometer more robust against environmental disturbances. Another consequence of the design is that the system becomes more compact and is now vacuum compatible. Such compatibility makes it very interesting when applications and positioning at nanoscales are considered. 


\section{B. Equations to compute the position}

The first step consists in the computation of a set of parameters that describes the displacements of the moving object along a parametric ellipse with 2 coordinates $X_{e}$ and $Y_{e}$. When interference patterns are recorded, at a sampling time $\mathrm{k}$, the 2 values are computed according to (1) and (2):

$$
\begin{aligned}
& X_{e}(k)=\frac{M_{2}(k)-R_{1}(k) * K_{1,2}+R_{2}(k) * K_{2,2}}{2 * \sqrt{R_{1}(k) * K_{1,2} * R_{2}(k) * K_{2,2}}} \\
& Y_{e}(k)=\frac{M_{2}(k)-R_{1}(k) * K_{1,2}+R_{2}(k) * K_{2,2}}{2 * \sqrt{R_{1}(k) * K_{1,2} * R_{2}(k) * K_{2,2}}}
\end{aligned}
$$

where $K_{i, j}, \forall(i, j) \in\{1,2\}^{2}$ are the internal parameters of the chip provided by the manufacturer.

The ellipse can be modeled as:

$$
\begin{gathered}
X_{e}(k)=A_{0} \cos (\phi(k))+X_{0} \\
Y_{e}(k)=B_{0} \sin \left(\phi(k)+\phi_{0}\right)+Y_{0}
\end{gathered}
$$

where $\left\{X_{0}, Y_{0}, A_{0}, B_{0}, \phi_{0}\right\}$ is a set of parameters which is identified online.

The second step is the computation of the position itself. The phase $\phi(k)$ is computed with (5) and (6):

$$
\begin{gathered}
\cos (k)=\frac{X_{e}(k)-X_{0}}{A_{0}} ; \sin (k)=\frac{Y_{e}(k)-Y_{0}}{B_{0} * \cos \left(\phi_{0}\right)}-\cos (k) * \tan \left(\phi_{0}\right) \\
\phi(k)=\operatorname{atan} 2(\sin (\phi(k)), \cos (\phi(k)))
\end{gathered}
$$

The incremental position $\Delta x(k)$ and the position $x(k)$ are finally such that:

$$
x(k)=x(k-1)+\Delta x(k) \text { with } \Delta x(k)=\frac{n \lambda \Delta \phi(k)}{4 \pi}
$$

where $\Delta \phi(k)=\phi(k)-\phi(k-1), \lambda$ is the wavelength of the source and $n$ the refractive index of air.

\section{EXPERIMENTS}

\section{A. Setup}

The main objective of the experiments that we have performed is to evaluate the intrinsic performances of the interferometer coupled with a dedicated 16 bits acquisition system. For this purpose, the interferometer chip in Fig. 2 is used.

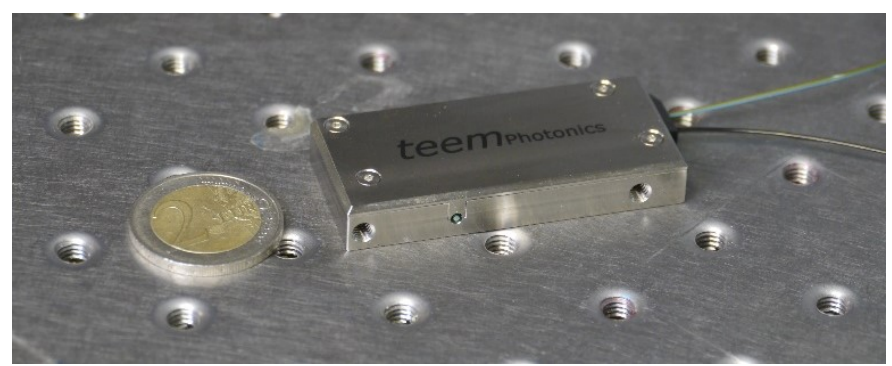

Fig. 2: Interferometer (PicoMove) used for the experiments
The laser source is a telecom laser module (ORION Rio0085-1-00-1) with a wavelength value of $1542.135 \mathrm{~nm}$. The mean power at the output of the optical chip for the useful moving arm is around $140 \mu \mathrm{W}$. The signal is processed with an embedded system based on a dsPic33 (dsPic33ep512mu810, Microchip). It allows 32 bits computation to deal with parameters that strongly affect the accuracy and the resolution of the system. For example, the refractive index of air must be stored with sufficient significant numbers to limit its uncertainty. Two analog to digital modules (AD7655, Analog Devices) process the four signals of the interferometer with hardware synchronization. The maximum frequency is 1 mega samples per second. The results are stored on two memory modules (N25Q512A, Micron).

One of the purpose of this paper is also to evaluate the performances of the system compared to more classical ones with acquisition boards with better resolution. The main reason for such a decrease is to provide the user with an affordable system. This is especially true as far as the final system requires multi degrees of freedom and consequently several positions sensors based on interferometry. We chose to compare 3 different systems available in our laboratory. The first one is the system described throughout this paper, the second one is based on a 24 bits National Instruments data acquisition board (NIPCI4472) and the third one is a 16 bits data acquisition board from the same manufacturer (NI-PXI6122). All these systems provide 4 simultaneous sampling channels.

\section{B. Results}

For the first experiment, we have computed the position at a frequency of $3 \mathrm{kHz}$ with our 16 bits embedded system.

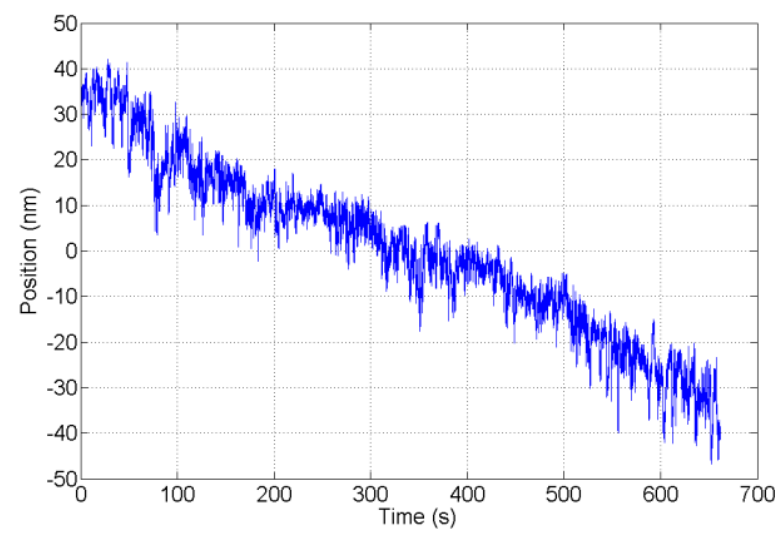

Fig. 3: Static position measurement

In Fig. 3, the position of the mirror is plotted with respect to the time. Data are recorded during 10 minutes. It is obvious that a drift appears on the plot and its origin is probably due to thermal or mechanical effects. Environmental conditions clearly influence the results but we are only interested in intrinsic performances of the interferometer. For this reason, it is necessary to plot differential values $x(k+1)-x(k)$ at each sampling time $\mathrm{k}$. Therefore, we can artificially compensate for drifts and focus on the performances of the optical chip and the acquisition board. 


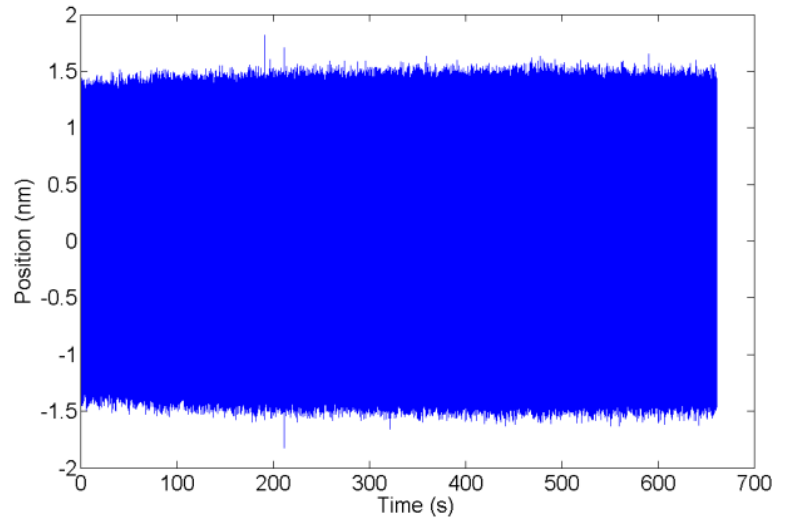

Fig. 4: Differential position of the static mirror obtained for static conditions

Differential position is thus plotted in Fig. 4. Drift is of course removed and typical noise is around $1.5 \mathrm{~nm}$. The remaining noise is mainly due to the vibrations in the building where experiments are performed. In Fig. 5, we are interested in the power spectral density of the interferometer.

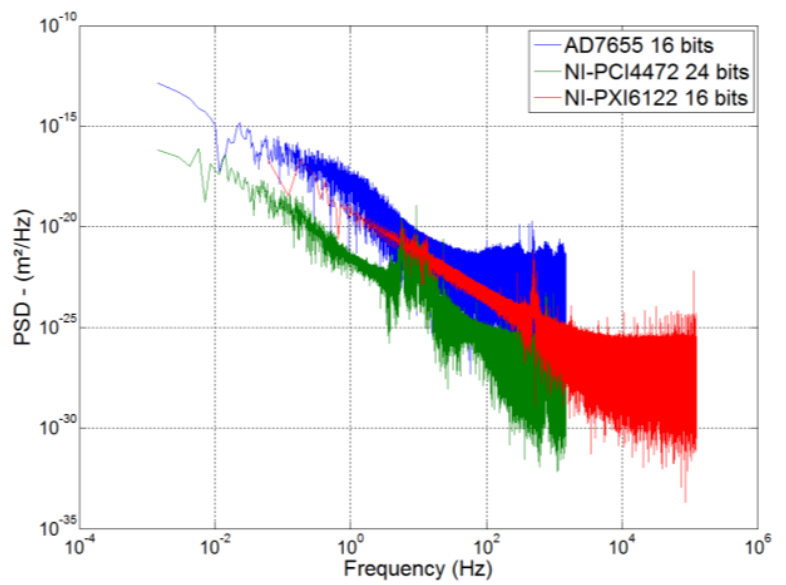

Fig. 5: Comparison of the power spectral density (PSD) for 3 different acquisition systems.

The system equipped with a 24 bits DAC (in green) exhibits the best performances according to the three different PSD noise levels. It is also noticeable that the performances are quite similar for the two 16 bits systems for lower frequencies (under $500 \mathrm{~Hz}$ ). The PSD noise level of the main system is around 5 pm. $\mathrm{Hz}^{-\frac{1}{2}} @ 10 \mathrm{~Hz}$ and seems to converge toward a level of $10^{-24} \mathrm{~m}^{2} \cdot \mathrm{Hz}^{-1}$ which corresponds to a noise level of 1 pm. $\mathrm{Hz}^{-\frac{1}{2}} @ 1.5 \mathrm{kHz}$.

Another key point is the low price of our DAC system compared to the two others. Including the power supply, which is the highest percentage of the price, the full DAC package is around
$50 €$. Again, that could make a huge difference when several sensors must be used together.

\section{CONCLUSION}

In this paper, we have presented an acquisition system which is suited to use with an interferometer chip. The electronic part is made to acquire 4 signals in a parallel way. The computation of the position is made with a homemade board based on a dsPic33. We have demonstrated with the experiments that the full system can achieve good performances regarding the noise level. It reaches $1 \mathrm{pm} . \mathrm{Hz}^{-\frac{1}{2}} @ 1.5 \mathrm{kHz}$. From our point of view, this embedded system can probably replace the system we have used previously on a computer for scanning applications.

However, for future work, it would be appreciable to add some filtering stages to increase again performances of the full system. Moreover, we would like to propose a closed-loop controller for surface topography applications based on the micro-controller board which was used in that paper.

\section{REFERENCES}

[1] A. Fleming, "A review of nanometer resolution position sensors: Operation and performance," Sensors and Actuators A, vol. 190, pp. 106-126, 2013.

[2] A. Yacoot and N. Cross, "Measurement of picometer nonlinearity in an optical grating encoder using $\mathrm{x}$-ray interferometry," Meas. Sci. Technol., vol. 14, pp. 148-152, 2003.

[3] A. Khiat, F. Lamarque, C. Prelle, P. Phouille, M. LeesterSchädel and S. Büttganbach, "Two-dimension fiber optic sensor for high-resolution and long-range linear measurements," Sensors and Actuators A, vol. 158 , pp. 43-50, 2010.

[4] L. Perret, L. Chassagne, S. Topcu, P. Ruaux, B. Cagneau and Y. Alayli, "Fiber optics sensor for sub-nanometric displacement and wide bandwidth systems," Sensors and Actuators A, vol. 165, pp. 189-193, 2011.

[5] A. Missoffe, L. Chassagne, S. Topcu, P. Ruaux, B. Cagneau and Y. Alayli, "New simple optical sensor: From nanometer resolution to centimeter displacement range," Sensors and Actuators A, vol. 176, pp. 46-52, 2012.

[6] N. Bobroff, "Recent advances in displacement measuring interferometry," Measurement Science and Technology, vol. 4, p. 907, 1993.

[7] A. Missoffe, S. Olivier, B. Cagneau, P. Millier, H. Guan and L. Chassagne, "Integrated waveguide interferometer with picometric performances," in IEEE/ASME International Conference on Advanced Intelligent Mechatronics, 2014. 